\title{
EL DERECHO ANTE LOS DESAFÍOS DE LA GLOBALIZACIÓN
}

DORA ESTHER AYALA ROJAS

FACULTAD DE DERECHO Y CIENCIAS SOCIALES Y POLÍTICAS - UNNE

"El autoritarismo ha mostrado la cara amarga de la derrota, junto a la muerte. Demos ahora una oportunidad a la paz, al diálogo y a la tolerancia" Federico Mayor Zaragoza 


\title{
RESUMEN
}

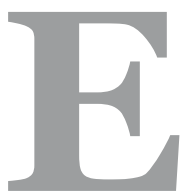

n la temporalidad de una nueva era, es necesario reflexionar acerca de los alcances de la globalización como fenómeno económico y su conexión con el mundo jurídico; relación que se presenta en muchos de sus despliegues, como un nuevo modo de revivir la antigua disputa entre la Economía y el Derecho por el protagonismo de las Ciencias Sociales. Con ese objetivo, el artículo describe los soportes teóricos del concepto de globalización y las respuestas del Derecho, expone la situación actual y propone algunas hipótesis con miras a superar la tensión existente, en un marco constructivista o de creación de significados mediante el trabajo colaborativo entre disciplinas. La construcción referida, no es atribuible a un único individuo ni a un grupo, sean personas o disciplinas, tampoco es singular ni unificada, sino compartida socialmente. Se resalta la importancia que tiene para esta perspectiva de análisis, la comprensión del Derecho con un sentido integrador de sus tres dimensiones: sociológica, normológica y valorativa; en la búsqueda de una interpretación más adecuada del sentido y de los intereses de la vida, que no se presentan lineales sino atravesados por complejidades y coberturas.

Palabras clave: complejidad, multidimensional, interdependencia, conexión, globalización, derechos humanos.

\begin{abstract}
Transient nature of new era, it is necessary to reflect about globalization achievement as an economic phenomenon and its connection with the legal world, Connection that it presents in many of its deployments as a new way to revive the old dispute between Economics and Law, for the prominent role of the Social Sciences. To that aim, this article, describes the theoretical support of the concept of globalization and the answers of the Law, expound the current situation and proposes some hypothesis in process of overcome the tension, in a constructivist framework or creation of meanings through by the collaborative Works between disciplines. The construction aforementioned is not attributable to a single individual or group, whetherpeoples or disciplines, neither is singular or unified, but socially shared. It highlights the importance that have for this perspective of analysis, understanding of the Law with a integration sense of the three dimensions: sociological, normological, and valuation, in a searching of one more suitable interpretation of the sense and the interest of life, that are not lineal but crossed complexities and coverages.-
\end{abstract}

Keywords: complexity, multidimensional, interdependence, connection, globalization, human rights. 
Transitamos un tiempo que acordamos llamar posmoderno, sabiendo que la expresión post modernidad por su nombre mismo, se constituye en relación aunque sea negativa con la modernidad transcurrida. No se es moderno, pero se es algo en relación con la modernidad (Ciuro Caldani, 2010). Este tiempo para algunos comenzó a anunciarse cuando estalló en Hiroshima la primera bomba atómica (6 de agosto de 1945), aunque otros ubican sus inicios al momento de presentarse ante la humanidad el genoma humano (14 de abril de 2003) ${ }^{1}$.

Cualquiera sea el punto de inicio que se adopte, lo cierto es que se transcurre la temporalidad de una nueva era, caracterizada como tal, porque presenta una dinámica mayor que una nueva edad, donde los cambios éticos, científicos y tecnológicos, son profundos y veloces, tal el caso de los avances en genética que posibilitan modificar la duración de la vida como sus cualidades, con importantes efectos en relación a la ética (Ciuro Caldani, 2010). En esta era, hay dos fenómenos que contribuyen a cambiar de modo muy notable los sistemas jurídicos de los países: la constitucionalidad y la globalización.

Con respecto a la primera, hay que reconocer que la expresión es ambigua. Puede referirse al fenómeno en sí como a la manera de conceptualizarlo: es decir, tanto al proceso que se da en el Derecho como a su concreción en el pensamiento de los juristas. Analizada como fenómeno, comparto la idea de que no supone solamente la existencia de sistemas jurídicos con algún tipo de Constitución, sino que refiere a la estructura de un organismo político, de un Estado, al diseño y organización de los poderes de decisión colectiva de una comunidad (Atienza, 2010); de modo que cualquier sistema jurídico cuya existencia presupone una organización y una voluntad política, tiene desde esta perspectiva, constitucionalidad, y así será considerada en este artículo.

Podría decirse que estamos ante fuerzas opuestas, porque mientras la constitucionalidad supone que el poder político debe respetar al Derecho y éste es de ámbito estatal, la globalización entiende más bien que el poder político está eclipsado por el poder económico y que su ámbito trasciende las fronteras de los Estados nacionales (Zimerman, 2005). Cabe mencionar que adoptada la expresión en el sentido apuntado arriba, el interés se desplaza hacia el fenómeno de la globalización como foco principal de la relación Economía - Derecho, dando por supuesta la existencia de una organización con voluntad política, estos, con constitucionalidad.

El problema que queremos dejar planteado es, si cabe pensar en algún tipo de sintonía entre ambos fenómenos, o si el Derecho quedará eclipsado; habida cuenta del poder que la Economía ejerce a escala global en una suerte de omnipresencia, de omnipotencia, inexorable e inevitable para su versión más absoluta; aunque no libre de críticas, que provienen desde el propio capitalismo (Stiglitz, 2003).

\footnotetext{
${ }^{1}$ Hay que aclarar que si bien un borrador inicial del genoma humano fue terminado en 2001 y anunciado al público conjuntamente por Bill Clinton y Tony Blair, el trabajo relativamente completo se dio a conocer recién en 2003. Ambas fechas son contundentes: el 6 de agosto de 1945 se comenzó a poner en cuestión la existencia de la vida en el planeta; el 14 de abril de 2003 se planteó el interrogante del porvenir de la especie humana.
} 
Con ese objetivo describiremos los soportes teóricos del concepto de globalización y las respuestas del Derecho, exponiendo la situación actual y proponiendo algunas hipótesis con miras a superar la tensión existente, desde un marco constructivista o de reasignación de significados mediante el trabajo colaborativo entre disciplinas.

\section{LA GLOBALIZACIÓN Y SUS DESPLIEGUES}

Aplicando el término en su sentido más general, aunque es sabido que se desenvuelve en múltiples direcciones, la noción de globalización o mundialización ${ }^{2}$ como también se denomina, es en principio, compleja (Sachs, 2008).

Se la puede definir como conjunto multidimensional de procesos sociales que crea, multiplica, despliega e intensifica, intercambios e interdependencias sociales a escala mundial (Rodríguez, 2011); a la vez que crea en las personas una conciencia creciente de conexión cada vez mayor entre lo local y lo distante (Stegel, 2003).

Desde una perspectiva economicista ${ }^{3}$, se trata de un proceso cuyo motor es el comercio internacional y los flujos de capitales (Ciuro Caldani, 2011); a los que se incorporan otros aspectos de índole social, cultural y por supuesto, tecnológica ${ }^{4}$.

El Derecho se ve en esta perspectiva como un receptor de los grandes cambios, convirtiéndose en un efecto de ellos; y es tal la fuerza de esa dinámica, que provoca cierto grado de obsolescencia en las instituciones, tanto jurídicas como políticas; y que al final también se extiende al cuerpo de conocimientos en general (Touraine, 2006).

La idea que hace circular esta postura es que el proceso de globalización avanza a velocidades mayores que el Derecho; y que a su vez en cada área de éste las velocidades son distintas.

Como consecuencia de ello, la conciencia que los teóricos del Derecho puedan tener acerca del fenómeno, se mueve con atraso.

\footnotetext{
${ }^{2}$ Se emplean estas dos palabras, en parte por una cuestión lingüística. No hay una traducción directa de globalización del inglés a otras lenguas que refieran estrictamente al fenómeno. De hecho la expresión ha sido difundida desde los países de habla inglesa, por eso se emplea también mucho en América Latina, mientras que en Europa se utiliza más, mundialización. Pero más allá de lo lingüístico hay también, creo yo, una diferencia de sentido. Mundialización alude a que los problemas tienen hoy cada vez más dimensión mundial, no son locales ni nacionales, por lo tanto involucran estructuras y autoridades que deben tener conciencia de esa situación. Así vista, es una expresión que se nutre de la teoría política. Globalización refiere a la apertura de fronteras, hasta el punto de pretender que ya no hace falta ninguna política para que circulen libremente todos los bienes materiales e inmateriales, sin intervención de ninguna autoridad. Así vista, es una expresión que se nutre de la teoría económica.

${ }^{3}$ Tiene su expresión más actual en el Análisis Económico del Derecho (AeD) que persigue la aplicación de la Teoría Económica para la explicación del Derecho. Su origen remonta a trabajos publicados en la década del sesenta del siglo XX, de un economista Ronald Coase y un jurista Guido Calabresi. Proviene de Universidades norteamericanas (Chicago y Virginia) e italianas (Génova). En general, se trata de una perspectiva reduccionista porque el hombre económico al que refiere es sólo una perspectiva del hombre y la reducción de la sociedad a un vasto mercado es sólo una perspectiva de sociedad. La eficiencia no es el único valor, sino uno de los valores a los que ha de referirse el Derecho, cuyo valor supremo se orienta a la Justicia, y aún más allá, a la propia humanidad.

${ }^{4} \mathrm{Si}$ bien es evidente que las personas globalizadas están mucho más cerca que antes de aprovechar los beneficios de la nueva era, también es cierto que los excluidos manifiestan diferencias inimaginables e inadmisibles con relación a ellos. Frente a esta tensión, la sociedad adquiere protagonismo y las minorías entran en conflicto con la organización total, defendiendo con distinto éxito lugares hasta no hace mucho desconocidos. Los desbordes financieros, las catástrofes, exhiben un Estado tradicional que exige reformularse.
} 
Consideramos que se trata de una versión reduccionista y también pesimista del Derecho... pero también hay que reconocer que alberga un muy fuerte impacto comunicacional (Albornoz, 2011); derivado de la idea que la velocidad para concretar los cambios es máxima referencia de valor y garantía de actualidad (Petras y Veltmeyer, 2003). En el mundo líquido posmoderno descripto por Bauman, la lentitud es sinónimo de muerte social. La presión del tiempo, la necesidad de congraciarse con el grupo de la moda (en el caso que pose sus ojos sobre uno, que advierta y tome nota de nuestro aspecto y/o de nuestro atuendo) y el limitadísimo número de opciones disponibles, son inconvenientes menores. Lo que importa es que uno esté realmente optando. En este juego, por más que la elección sea de uno, elegir es una obligación. Para la cultura consumista, elegir y ser libre son una misma cosa (Bauman, 2008). Por esas razones, pensar en el occidente posmoderno es referirse a un fuerte impulso de cambio; sólo el cambio hace posible el consumo que se pretende (Ciuro Caldani, 2010).

\section{LAS RESPUESTAS DEL DERECHO}

Las primeras reacciones de los teóricos del Derecho que procuran recuperar su protagonismo frente a la avasallante Economía global, recurren a argumentos que reviven la antigua polémica entre jus naturalismo y jus positivismo.

Los primeros, agrupados bajo el nombre de no positivistas, sostienen que es necesario abandonar el positivismo jurídico y construir un concepto de Derecho acorde con su naturaleza doble, o de dos dimensiones: real o fáctica, que comprende promulgación adecuada y eficacia social; e ideal o crítica, que comprende la corrección moral. La primera dimensión aboga por un concepto positivista del Derecho. Cuando se agrega la segunda, surge un concepto no positivista del derecho (Alexy, 2008). Los que se pronuncian en contra de la globalización desde una posición positivista, entienden al Derecho como fenómeno de autoridad estatal. En una versión actual, aclaran que aquél no se identifica ya con la ley en sentido estricto, sino con la Constitución (Ferrajoli, 2009) Este despliegue del positivismo implica que el Derecho deje de entenderse en términos puramente descriptivos, asumiendo la función crítica de mostrar las contradicciones de las normas con la Constitución, para corregirlas5. El principal argumento de los no positivistas - que hoy conforma la posición mayoritaria - sostiene que podría pensarse en un Derecho alicaído frente la Economía, si se lo considera como estatal o internacional en el significado clásico de la expresión: un derecho cuyos actores son fundamentalmente los Estados; pero el panorama sería distinto si en lugar de enfocar la mirada en el Derecho como sistema jurídico formal, se considerara la juridicidad con una base sujeta no al legalismo como autoridad, reglas y subsunción - sino a un sistema de valores expresado en los principios.

\footnotetext{
${ }^{5}$ En igual sentido, la exposición del Dr. Ramón de la Cruz Ochoa en su ponencia "Acerca del pensamiento de L Ferrajoli", en el Encuentro internacional de Historia del Derecho, Filosofía y Sociología Jurídica, realizado en Homenaje al Profesor Dr. Julio Fernández Bulté, en la Facultad de Derecho de la Universidad de la Habana, del 23 al 25 de febrero de 2010.
} 
El rasgo sobresaliente de esta posición, en términos de globalización jurídica, se traduce en una tendencia a la privatización del Derecho, mediante el surgimiento de reglas institucionales homogéneas que respondan al funcionamiento de la economía global y armonicen los sistemas nacionales mediante un proceso de abstracción, utilizando conceptos jurídicos indeterminados y cláusulas generales. (Lorenzetti, 2004).

El centro de gravedad se traslada de la Ley, como producto de la voluntad estatal, a los contratos entre particulares (aunque esos particulares sean en su mayoría las grandes empresas multinacionales) por lo que se menciona una tendencia general a la contractualización de los conceptos jurídicos. De este modo, la globalización se inicia y se desarrolla priorizando el valor utilidad, requiriendo una organización acorde de las herramientas jurídicas, no sólo para satisfacer necesidades económicas sino también culturales.

En este panorama, el contrato se presenta como uno de los instrumentos de mayor eficacia; y fuente primordial de las relaciones patrimoniales (Garrido Cordobera, 2006). En la pugna por globalizar, el poder económico procura imponer sus modelos contractuales en el derecho interno, dando origen a un pluralismo jurídico de derecho o de hecho, donde quizás el mejor modo de evitar sus efectos negativos, consista en proteger las fuentes nacionales para una recepción equilibrada del derecho extranjero (Nicolau, 2005).

El proceso en análisis, está acompañado de una creciente pérdida o transformación de la noción de soberanía por parte de los Estados, como consecuencia del avance tanto del Derecho supranacional como transnacional, con preeminencia del valor de los tratados. Para su consolidación, se menciona el éxito del proceso integrador de la Unión Europea, aunque también es evidente la crisis -al menos parcial- que aqueja a la estructura formal de la comunidad europea, exteriorizada en las múltiples manifestaciones de inmigrantes y extranjeros; y las tensiones entre las comunidades más y menos avanzadas. Estos problemas afectan, más allá de los límites de la Comunidad Europea, a la sociedad toda en términos globales.

Como ejemplo de la consolidación de la Comunidad Europea suele citarse la existencia de un Derecho Europeo Comunitario, que supone que una buena parte de las normas jurídicas vigentes en los Estados, están fuertemente condicionadas por normas supra estatales.

También, acompaña este proceso, la vigencia de una lex mercatoria que rige el comercio internacional y no es elaborada ni por los Estados Nacionales ni por Instituciones Públicas internacionales, sino por los grandes bufetes o despachos de abogados en red internacional.

La lex mercatoria tiene sus principales despliegues en la figura del contrato. En su expresión latina, es el conjunto de usos del comercio internacional elevado a un rango jurídico distinto y diferente al Derecho nacional. Se trata de un sistema consuetudinario tras nacional, que influye en las fuentes internas mediante los aportes de la doctrina y la jurisprudencia, que van remitiéndose a ellas con toda naturalidad. (Nicolau, 2005). Es bien conocida la Convención de Naciones Unidas sobre Contratos de compraventa internacional de mercaderías (Viena, 1980) que contiene principios que rigen la formación del contrato y con notable influencia 
en los procesos de reforma de los Códigos Nacionales. También, el desarrollo de tipos contractuales que se han impuesto en las transacciones globales, como el leasing y el factoring.

Asimismo, estas mutaciones se manifiestan en la crisis de las delimitaciones territoriales, a veces con fuerte debilitamiento del Estado Nación, que conllevan a la Teoría Política a una re conceptualización de la noción de territorio. En el modelo tradicional, la democracia ha tenido siempre como base, al Estado Nación. Este anclaje territorial es el primer criterio que permite determinar quién es o no, ciudadano. Actualmente, su puesta en tela de juicio, a partir del surgimiento de unidades políticas y económicas que comprenden a varios Estados; y la presencia de movimientos migratorios con grandes grupos de extranjeros al interior de los sistemas nacionales, implican nuevos diseños institucionales, nuevas prácticas y nuevos mecanismos de decisión (Respuela, 2005).

Con relación a las personas, la transformación aludida produce el resquebrajamiento de las relaciones interpersonales que conforman la base de la malla social; y los grandes protagonistas del Derecho globalizado ya no son los legisladores sino los jueces y los especialistas que no ocupan cargos públicos: Así por ejemplo, el Tribunal de Luxemburgo ha jugado un papel decisivo en la actual configuración del Derecho Europeo y los árbitros que deciden los pleitos del comercio internacional son abogados expertos, consultores privados y/o profesores universitarios.

Se habla de un nuevo tipo de Derecho, un soft law ${ }^{6}$, para el que recurrir a la coacción es menos importante que antes, que se manifiesta en la tendencia a promover mecanismos de resolución de conflictos (como la mediación y el arbitraje); que frente a la jurisdicción parecen no tener carácter de imposición porque presuponen la aceptación por las partes, quienes nombran a los mediadores y árbitros; y que le otorga la máxima importancia a organismos como la Organización Mundial del Comercio, regida por normas distintas, superiores y a veces contrarias, a las del clásico derecho estatal7.

Este derecho soft no consiste ya exclusivamente en prescripciones, sino en pautas de comportamiento que tratan de guiar la conducta de manera flexible, sin pretender imponerse coactivamente. Tal el caso de las Directivas del Derecho Comunitario y la importancia creciente de los Códigos de Ética como mecanismos de auto regulación. Esta situación es referida como una elastización en el funcionamiento de las normas (Ciuro Caldani, entrevista personal concedida a Flor Ávila de Pulitano, 2008); y ha llevado a una difuminación de los límites tradicionales del Derecho y de las distinciones clásicas entre Derecho Privado y Derecho Público,

${ }^{6}$ El derecho suave está integrado por las resoluciones de organismos internacionales, recomendaciones de naturaleza no coercitiva o no estrictamente obligatoria, aunque tampoco son simplemente éticas. El Derecho duro o fuerte se integra con los tratados. Una consecuencia del Derecho suave, es su correlato: la responsabilidad suave. La diferencia se planteó originalmente en el derecho internacional para resolver cuestiones ambientales, pero hoy está extendida también al Derecho interno para resolver situaciones de responsabilidad.

${ }^{7}$ La Organización Mundial del Comercio nace en Marruecos en 1994, tiene su sede en Ginebra (Suiza) y comienza a funcionar en 1995, para regular el comercio mundial. En lo que respecta al contenido de este artículo, se resalta que la OMC tiene normas y procedimientos especiales de resolución de conflictos, tales como la comunicación, la conciliación voluntaria y el arbitraje. Las diferencias son sometidas al Comité de Expertos, que emite opinión al Consejo General. 
o entre Derecho interno y Derecho externo (Ciuro Caldani, 2003).

La disminución de la profundidad de las referencias culturales (Bauman, 2009) ha puesto en discusión algunos conceptos como los que refieren al reproche penal en relación con el reconocimiento del principio de jurisdicción universal cuando se trata de crímenes de lesa humanidad o el de su imprescriptibilidad (Erbetta, 2005); y en el Derecho de Familia, transformando desde el propio concepto de familia al de los institutos específicos, como la restitución de menores ((Perugini Zanetti, 2005).

Es evidente que los cambios más importantes se producen y se producirán sobre la noción de persona, en especial, por las posibilidades de la reproducción y la genética.

En ese sentido, la especie humana no ha tenido sobre sí misma un poder similar al que hoy posee. En ese recorrido, algunas perspectivas son menos innovadoras, como las uniones de hecho y las familias ensambladas y otra lo son más, como la unión civil, el matrimonio igualitario, la reproducción asistida y la clonación. Estas complejidades llevan a decir que una familia es lo que es y no lo que dice el universal (Ciuro Caldani, 2010). También a considerar que el hombre, modificado por otros hombres, incidirá de manera diversa en la filiación, el matrimonio, los contratos, las sucesiones, los derechos de la niñez y de la vejez (Dabove Caramuto, Prunotto Laborde, 2006).

Con estas novedades, nacen y se desarrollan nuevas ramas jurídicas destinadas a enriquecer, no a sustituir, a las tradicionales. Por ejemplo, ya están en pleno auge el Derecho de la Salud, el Bioderecho, El Derecho del Arte, El Derecho de la Ancianidad, El Derecho de la Educación, El Derecho de la Universidad (Ciuro Caldani, 2007), El Derecho Urbanístico (López Ramón, 2005) etc. Estas nuevas ramas acompañan la evolución de otras que ya avanzaron un poco más, como el Derecho Ambiental (Lorenzetti, 2008) y el Derecho del Consumidor (Castellano, 2006).

\section{LA SITUACIÓN ACTUAL: ALGUNAS HIPÓTESIS PARA EL ANÁLISIS}

En este avance y durante todo el siglo XX hasta hoy, el fenómeno de la globalización ha extendido sus efectos sobre el Derecho, de manera continua. Pero ese universo global que es mostrado como panacea, lejos de resolver los conflictos de la humanidad, muestra tensiones cada vez mayores entre pocos favorecidos y muchos perjudicados (Galeano, 2011).

Es aquí donde la teoría política y la sociológica hacen su aporte, aproximando y fortaleciendo algunas posturas contrarias a los efectos globalizantes como garantes de felicidad y único destino posible para la humanidad (Treber, 2005). En particular, al sostener que los procesos de liberalización, de desregulación, han sido acompañados de falta de garantías hacia los Derechos humanos, en especial de los Derechos sociales (Caruso y Tenorth, 2011). En este sentido, el jurista actual debe ser crítico de la sujeción de los Derechos humanos y la democracia, al economicismo; de la esclerosis que sufre la constitución política y de la falta de desarrollo académico del Derecho (Ciuro Caldani, 2008). 
Además, y para preservar, actualizar y proyectar el acervo jus filosófico del lugar donde se encuentra, la Universidad debe otorgarle un muy importante papel a la investigación (de Souza Santos, 2005) concretando una reforma democrática y emancipadora. Es indudable que no será solamente con ella, pero también está claro que es en ella donde naturalmente se produce.

La riqueza del mundo concentrada, principal efecto del capitalismo global, se hizo a costa de profundizar desigualdades entre países y entre individuos (Stiglitz, 2003) y es sabido que la desigualdad en cualquiera de sus formas, promueve la degradación y la corrupción (Roger, 2004).

En esta perspectiva, la posición más extrema sostiene que el Derecho de la globalización es claramente un Derecho no democrático e implica un retroceso en la concreción de un derecho humanista (Louge Emiliozzi, 2005). A esta altura, cabe preguntarnos si frente al desplazamiento de la esfera pública y de la política, podemos todavía hablar de democracia. No hay que olvidar que existe un nexo necesario entre el demos (o cuerpo colectivo, conjunto de personas unidos por cultura, lengua y valores comunes) y la democracia (Bayón, 2010).

La situación expuesta nos convoca a pensar nuevas hipótesis que definan el papel del Derecho y de sus operadores en la sociedad global. Algunas podrían surgir en torno a los siguientes puntos:

1.- Con una mirada mínimamente realista sobre el devenir del mundo, reconocer que la globalización es un fenómeno que ha llegado para quedarse; y admitir en consecuencia, que el Derecho no será ya lo que era.

Considerar al Derecho como un resultado esencialmente estatal, un conjunto de normas establecidas por la autoridad del Estado, resulta cada vez más insatisfactorio; aunque esa visión pueda reflejarse todavía en alguna de sus ramas, como el Derecho Penal o el Derecho Tributario. Por lo tanto, es cierto que lo que esencialmente tiene en cuenta un juez penal son las leyes penales y el encapsulamiento derivado de la tipicidad, pero aún así el principio de jurisdicción universal reconocido por algunos ordenamientos estatales en relación con los crímenes de lesa humanidad, y su imprescriptibilidad, tienen importantes consecuencias en el Derecho Penal actual. Por ejemplo, algunos tribunales constitucionales niegan la validez de la ley de amnistía que dictan los estados para garantizar inmunidad (Atienza, 2010). En materia tributaria, ocurre algo similar con la determinación del hecho imponible y el principio de la realidad económica (Damarco, 2010.)

En otras ramas del Derecho, la incidencia de la reglamentación supraestatal, se presenta como una exigencia del intercambio en contextos más veloces, difuminados y abarcativos de relaciones entre proveedores y consumidores (Mosset Iturraspe y Piedecasas, 2004). El comercio internacional, internet, los movimientos migratorios, el ambiente, la protección contra el terrorismo, etc., son cuestiones que no pueden regularse eficazmente en el ámbito nacional o internacional, entendido éste en su sentido clásico.

En realidad, no se trata de que el Derecho haya dejado de ser un fenómeno estatal, sino de asumir que la juridicidad no se agota en la estatalidad. Existe una juridicidad por fuera y por so- 
bre los Estados, cuyo peso tiende a ser cada vez mayor y con la que tenemos que aprender a convivir, a criticar, a construir; sin relegar la conservación de identidades y culturas, con un diálogo que atraviesa continentes y va acompañado de novedosas prácticas (Gergen y Gergen, 2011).

2.- En materia obligacional, hay que admitir que el contrato constituye la forma típica de juridicidad global y que el debilitamiento de la institucionalidad, favorece la contractualidad. La trama institucional cede ante la individualidad personal, provocando cambios en los procesos de socialización, los que a su vez se traducen en cambios del sentido contractual clásico (Lorenzetti, 2004).

En estas nuevas formas de acordar, el Derecho tiende a verse menos como el producto de una voluntad política entre las partes que intervienen y adquiere más importancia como un medio para obtener ciertos fines, como un mecanismo de construcción en red social estratégica (Atienza, 2010).

Es así que las personas al consentir o tomar decisiones en la sociedad global, lo hacen en una situación cada vez más fuerte de inter dependencia con otros sujetos que la mayoría de las veces ni siquiera conocen, pero a los que están ligados a través de múltiples hipótesis de comportamiento.

3.- Hay que reconocer que el Derecho en sentido global, tiende a alejarse de una concepción positivista, en el sentido que ya no es visto como un sistema cerrado, lineal, como conjunto de normas preexistentes sino como una práctica, como un procedimiento, o un método para conciliar intereses o resolver conflictos (Dabove, 2009); caracterizados por una marcada presencia del capital financiero, que puede penetrar e intervenir en todos los aspectos de la vida, desde la propiedad inmueble hasta la genética.

Esta idea supone una manera nueva de entender la función del Derecho: no se trata tanto de describir el objeto jurídico, que está ya completamente determinado, cuanto de partir de allí y mostrar cómo puede usarse para operar en la práctica y lograr determinados objetivos, para que el reparto proyectado llegue a ser reparto realizado (Ciuro Caldani, 2008). El Derecho es considerado así, un quehacer; un hacer tareas.

La dinámica jurídica señalada, adquiere importancia significativa porque desplaza a la burocracia, tan perjudicial en los tiempos globales, donde la quietud es más negativa que cualquier movimiento y donde a veces es necesario desenmascarar la cobertura con que el anquilosamiento o la sedimentación han revestido a las normas, para proteger intereses de por sí rechazables (Ciuro Caldani, 2007).

4.- Se hace necesario advertir la importancia de otros condicionantes: sociales, históricos, políticos, contextuales, etc.; y comprender que ellos integran una complejidad integrada por las dimensiones: sociológica, normativa (normológica) y valorativa (dikelógica) de lo jurídico (Goldschmidt, 1987).

Creemos que se puede lograr una vuelta de tuerca para este papel secundario del Derecho, si consideramos que estamos inmersos en sociedades que tienden a ser inexorablemente 
jurídicas, porque las regulaciones no se limitan a establecer pautas para cierto tipo de relaciones, sino a considerar también los condiciones de los repartos para esas pautas y la intervención de valores (Dabove, 2011).

La sociedad asumirá formas muy diversas de regulación según sus pautas culturales y valorativas. La norma como reparto proyectado, también lo hará. Por eso, la nueva era reclama a la sociedad que se apoye en la educación y en la investigación para desenvolver mejor las potencialidades, en una apertura siempre abierta a la esperanza. Hay que tener presente que los momentos históricos pueden ser de cultura, con más fortaleza valorativa, de civilización, donde los valores son menos fuertes o están difusos entre sí, y de decadencia, cuando éstos entran en crisis (Ciuro Caldani, 2010).

Además, corresponde considerar para la interpretación de la globalización el papel fundamental de los Derechos humanos, como criterios inspiradores de las prácticas jurídicas y que tienen su fundamento en la ética; pero no cualquier postura ética, sino en la ética universal (Alegre y Gargarella, 2007); ya se considere que estos criterios inspiradores -principios- tienen validez objetiva, o construida. La adhesión social a los Derechos humanos no se produce en forma espontánea, requiere de una enseñanza y un aprendizaje, es decir de una Paideia. Los derechos humanos están fundamentados en y orientados hacia un sistema de valores que no se pueden imponer (Pérez Luño, 2009).

5.- Y la última hipótesis -que bien puede ser la primera- refiere al Derecho como construcción cultural (Gergen y Gergen, 2011) que pretende mejorar la vida de las personas Más aún, el conocimiento jurídico tiene como meta a la vida humana; y eso requiere un gran esfuerzo de profundización para comprender sus grandezas y limitaciones. Hay que criticar y proponer mucho más ahora que antes o al menos con más rapidez, y para ello hay que apoyarse en el desarrollo de la capacidad de preguntar. (Ciuro Caldani, 2003).

Nos parece interesante lo que en ese sentido expresa Manuel Atienza, al sostener que en el entramado social, el desarrollo de la capacidad de preguntar permite distinguir cuatro tipos de personas: los avispados, los idiotas, los parias y los cívicos (Atienza, 2010).

Los avispados son los que logran situarse en una posición de ventaja, porque saben aprovechar sus oportunidades y actúan sin muchos frenos éticos ${ }^{8}$. Los idiotas, pueden pertenecer al campo de los privilegiados o de los desventajados, pero no son conscientes de su posición por no interesarse por la cosa pública ${ }^{9}$.

Los parias, no están reconocidos socialmente por lo que siempre se encuentran en situación de desventaja, aunque no por su culpa sino por la acción combinada de avispados e idiotas ${ }^{10}$.

\footnotetext{
${ }^{8}$ En general los Diccionarios refieren al término avispado como un adjetivo que indica astucia, sagacidad, agudeza, vivacidad.

${ }^{9}$ El idiota en la Grecia Clásica era el ciudadano privado y egoísta, considerado así porque no se preocupaba por los asuntos de la polis, los asuntos públicos. En la Edad Media, refirió a la persona sin educación o ignorante por falta de conocimiento del latín. Para ellos era necesaria la traducción de los textos a las lenguas romances "ad usum idiotarum". El sentido actual del término está asociado al aislamiento y a la estupidez. Manuel Atienza enfoca en el primer significado.

${ }^{10} \mathrm{El}$ paria o intocable en la cultura hindú es la persona que pertenece al más bajo de los grupos sociales, "los sin casta", su vida es considerada impura y un roce con él, puede contaminar. La acción de Gandhi posibilitó la abolición constitucional de la intocabilidad en 1955 pero la discriminación social aún subsiste.
} 
Los cívicos tratan que la sociedad sea más igualitaria ${ }^{11}$ y para ello procuran poner límites a los avispados, despabilar a los idiotas, e incluir a los parias.

Finalmente afirma que la globalización ha contribuido hasta ahora, a enardecer los ánimos de los avispados y aumentar el número de los idiotas y de los parias; pero el reclamo social pendiente apunta a la formación de ciudadanos cívicos.

En definitiva, la globalización como todo fenómeno vital tiene efectos beneficiosos y perjudiciales. Es interesante observar cómo ha creado una soberanía nueva, supra estatal, difusa y poli céntrica, se habla incluso de una post soberanía, que ha relativizado el papel tradicional de los Estados, pero que también ha revalorizado el Derecho (García Figueroa, 2009).

Sus beneficios se evidencian cuando incrementan las posibilidades de contacto cultural, de contacto de vida, con todos sus despliegues: artísticos, sociales, políticos, educativos, etc.

Sus perjuicios se marcan cuando se establece como una "oquedad"12, en la magnífica expresión de Miguel Ángel Ciuro Caldani; esto es, vaciando a las personas, a los pueblos y a las culturas, mediante la acción de poderes externos que desconocen y avasallan a la humanidad, que es el más importante y abarcativo de todos los valores (Ciuro Caldani, 2010).

Y es el Derecho, como constructor de repartos, que se proyectan en normas y se valoran mediante la Justicia ${ }^{13}$, quien no solamente puede, sino además, le corresponde señalarlo.

\section{REFERENCIAS BIBLIOGRÁFICAS}

Albornoz, L. (Comp.). (2011). Poder, medios, cultura. Buenos Aires: Paidós.

Alegre, M. y Gargarella, R. (Coord.). (2007). El Derecho a la Igualdad. Aportes para un constitucionalismo igualitario. Buenos Aires: Lexis Nexis.

Alexy, R. (2008). La doble naturaleza del derecho. Conferencia con motivo de recibir el título de Doctor Honoris Causa de la Universidad Nacional de Tucumán. San Miguel de Tucumán, República Argentina.

Atienza, M. (2010). Constitucionalismo, globalización y derecho. En Carbonell M. y García Jaramillo L. (Eds.) El Canon neo constitucional (pp. 264-281) Madrid: Trotta.

\footnotetext{
${ }^{11}$ La expresión "cívico" califica al ciudadano como perteneciente a la ciudad (civitas). Comprende a las personas legalmente reconocidas por el Estado, como titulares de derechos y deberes. Se construye y fortalece con la Teoría del Estado de Derecho en su versión tradicional y renovada mediante la Teoría de los Derechos Fundamentales. El civismo es la virtud de quienes se involucran con la vida de la ciudad. Para marcar la evolución desde el Estado de Derecho Tradicional hacia el Estado Universal, quizá sea más adecuada, en la clasificación de Atienza, la referencia a personas políticas, en el sentido de la polis griega, que a personas cívicas.

12 Los Diccionarios la definen como cavidad, hueco intersticio.

${ }^{13}$ La Teoría trialista del Mundo Jurídico fundada por Werner Goldschmidt y representada por Miguel Ángel Ciuro Caldani en su versión más actual de la que participamos, sostiene que ese mundo ha de ser construido incluyendo repartos de potencia e impotencia (dimensión sociológica) captados normativamente (dimensión normológica) y valorados por un complejo de valores que culmina en la Justicia, como adjudicación a cada persona de la esfera de libertad necesaria para su desarrollo pleno (dimensión dikelógica)
} 
Aznar, L. y De Luca, M. (Coord.). (2007). Política: Cuestiones y problemas. Buenos Aires: MC.

Bauman, Z. (2009). Múltiples culturas, una sola humanidad. Buenos Aires: Katz.

Bauman, Z. (2008). Vida de consumo. Buenos Aires: Fondo de cultura económica.

Bayón, J. C. (2010). Democracia y derechos: problemas de fundamentación del constitucionalismo. En Carbonell M. y García Jaramillo L. (Eds.) El Canon neo constitucional (pp. 285-355) Madrid: Trotta.

Caruso, M. y Tenorth, H. (Comp.) (2011). Internacionalización. Políticas educativas y reflexión pedagógica en un medio global. Buenos Aires: Granica.

Castellano, A. (2006). El análisis económico del derecho del consumidor: información, garantías y daños por productos elaborados. En Kluger V. (Comp.). Análisis económico del derecho. (pp. 155-176) Buenos Aires: Heliasta.

Ciuro Caldani, M.A. (2010). Estudios jurídicos del Bicentenario. Rosario: UNR.

Ciuro Caldani, M. A. (2008). Entrevista concedida a Flor Ávila de Pulitano para la Revista Fronesis, de Filosofía Jurídica, Social y Política del Instituto de Filosofía del Derecho Dr. J. M. Delgado Ocando de la Universidad del Zulia. Obtenida el 10 de enero de 2011 de http:// www.revistas.luz.edu.ve/index.php/frone/article/view/400/371

Ciuro Caldani, M. A. (n. d.). Aportes del Análisis Económico del Derecho para la teoría trialista del mundo jurídico. Obtenida el 12 de mayo de 2011 de http://www.centrodefilosofia. org.ar/YyD/Invest y Doc.pdf

Ciuro Caldani, M. A. (2008). Metodología jurídica y lecciones de historia de la filosofía del derecho. Rosario: Fundación para las investigaciones jurídicas.

Ciuro Caldani, M. A. (2007). Las partes y el todo en la teoría trialista del mundo jurídico. En Ciuro Caldani M. A. (Coord.) Dos filosofías del derecho argentinas anticipatorias. Omenaje a Werner Goldschmidt y Carlos Cossio. (pp. 37-48). Rosario: Fundación para las investigaciones jurídicas.

Ciuro Caldani, M. A. (2003). Lecciones de filosofía del derecho privado (história). Rosario: Fundación para las investigaciones jurídicas. 
Dabove, M. I. (n. d.) Cincuenta años después... ¿Por qué es importante la dikelogía en el derecho?. Investigación y Docencia. Obtenida el 13 de mayo de 2011 de http://www.cartapacio. edu.ar/ojs/index.php/iyd/article/viewFile/1278/1380

Dabove, M. I. (2009). El funcionamiento del derecho en la teoría trialista. En Bentolila J. J. (Coord.) Introducción al derecho. (pp. 99-110). Buenos Aires: La Ley.

Dabove Caramuto, M. I. y Prunotto Laborde, A. (Dir.) (2006). Derecho de la ancianidad. Perspectiva interdisciplinaria. Rosario: Juris

Damarco, J. (Dir.) (2010). Tratado jurisprudencial y doctrinario de derecho tributario. Tomo I. Buenos Aires: La Ley.

De Souza Santos, B. (2005). La Universidad el siglo XXI. Buenos Aires: Miño y Dávila.

Erbetta, D. (2005). Postmodernidad y globalización: hacia dónde va el Derecho Penal?. En Alterini A. y Nicolau N. (Dir). El Derecho Privado ante la internacionalidad, la integración y la globalización (pp. 75-88). Buenos Aires: La Ley.

Ferrajoli, L. (2009). Pasado y futuro del Estado de Derecho. En Carbonell M. (Ed.), Neo constitucionalismo (pp. 13-29) Madrid: Trotta.

Galeano, E. (2010). Las venas abiertas de América Latina. Buenos Aires: Siglo XXI.

García Figueroa, A. (2009). Criaturas de la moralidad. Madrid: Trotta.

Garrido Cordobera, L. M. R. (2006).La negociación contractual y el análisis económico. En Kluger V. (Comp.) Análisis económico del Derecho (pp. 143-154) Buenos Aires: Heliasta

Gergen, K. y Gergen, M. (2011). Reflexiones sobre la construcción social. Madrid: Paidós.

Goldschmidt, W. (1987). Introducción filosófica al derecho. $6^{\circ}$ Ed. Buenos Aires: Depalma.

López Ramón, F. (2005). Introducción al derecho urbanístico. Madrid: Marcial Pons.

Louge Emiliozzi, E. (2005). Bases para la caracterización de un Derecho Privado Humanista. En Alterini A y Nicolau N (Dir). El derecho privado ante la internacionalidad, la integración y la globalización (pp. 117-124). Buenos Aires: La Ley. 
Lorenzetti, R. (2008). Teoría del derecho ambiental. Buenos Aires: La Ley.

Lorenzetti, R. (2004). Tratado de los contratos. Parte general. Buenos Aires: Rubinzal - Culzoni.

Mosset Iturraspe, J. y Piedecasas, M. (Dir.) (2004). Código Civil Comentado. Doctrina Jurisprudencia - Bibliografía. Contratos. Parte General. Buenos Aires: Rubinzal - Culzoni.

Nicolau, N. (2005). El derecho contractual frente al plurijuridismo, la integración y la globalización. En Alterini, A. y Nicolau, N. (dir). El Derecho Privado ante la internacionalidad, la integración y la globalización. Homenaje al Profesor Miguel Ángel Ciuro Caldani (pp. 423434) Buenos Aires: La Ley.

Pérez Luño, A. (2009). La filosofía del derecho en perspectiva histórica. Sevilla: Universidad de Sevilla.

Perugini Zannetti, A. (2005). La restitución internacional de menores, el derecho procesal internacional y el derecho internacional privado. En Alterini A y Nicolau N (Dir.) El derecho privado ante la internacionalidad, la integración y la globalización (pp. 509-536). Buenos Aires: La Ley.

Petras, J. y Veltmeyer, H. (2003). Un sistema en crisis: la dinámica del capitalismo de libre mercado. Buenos Aires: Lumen.

Respuela, Sofía. (2005). La democracia: una discusión en torno a sus significados. En Pinto, J. (com.). Introducción a la Ciencia Política (pp. 271-320) Buenos Aires: Eudeba.

Rodríguez, C. (2011). Lecciones de Economía Política. Corrientes: Moglia.

Roger, J. (2004). Argentina, América Latina y la globalización económica. Buenos Aires: Lumiere.

Sachs, J. (2008). Economía para un planeta abarrotado. Buenos Aires: Debate.

Stegel, M. B. (2003) Globalization, a very short introduction, Oxford: OUP.

Stiglitz, J. (2003). El malestar de la globalización. Buenos Aires: Taurus. 
Touraine, A. (2006). Un nuevo paradigma. Buenos Aires: Paidós.

Treber, S. (2005). Economía mundial. Claves para el siglo XXI. Córdoba: El Emporio.

Zimerman, H. (2005). Transición democrática y nuevas formas de hacer política. Corrientes: Moglia.

\section{CURRÍCULUM VITAE:}

Máximo grado académico obtenido en el exterior: Especialista en Derecho Tributario (Universidad de Salamanca, 2003). Máximo grado académico obtenido en el país: Especialista en Derecho Tributario (Universidad Nacional del Litoral, 2002), Especialista en Docencia Universitaria (Universidad Nacional del Nordeste, 2002). Cargos académicos y científicos actuales: Profesora Titular Regular (d.2005) de Derecho Financiero y Tributario. Profesora Adjunta Regular (d.1991) de Economía Política - Régimen Mayor Dedicación (d.1998). Investigadora Categorizada Nivel III (d.2005).Directora de Proyectos de Investigación acreditados de la UNNE (d.2006). Miembro Activo de la Asociación Argentina de Estudios Fiscales (d.2007). dorayala@gigared.com 